\title{
GREEN HUMAN RESOURCE MANAGEMENT - PERFORMANCE MANAGEMENT AND EVALUATION
}

\author{
Almira Curri-Memeti \\ Department of Marketing and Management, Faculty of Economics \\ almira.curri@unite.edu.mk \\ Diar Selimi \\ Department of Marketing and Management, Faculty of Economics \\ diar.93@hotmail.com
}

\begin{abstract}
The concern for the natural environment began a long time ago. Throughout the previous two decades, the globe appealed for proactive ecological management. The term eco-friendly or environmentally friendly is also widespread nowadays, relating to laws, activities, products, services etc., theatre having, minimal, reduced or not having negative impact on eco-systems and the environment. Environmental performance is the relationship between the organization and the environment. Current writing on environmental management recognizes that with a specific end goal to accomplish environmental sustainability objectives, associations can use proper human resource management practices to motivate their employees. To this end, incredible endeavors have been made to investigate what drives workers to participate in proecologic practices that help their organization to turn green and be sustainable. Additionally, a number of studies demonstrate that there is a connection among the green activities, organizational performance and corporate profitability within any association. The main purpose behind this thesis is to extend our understanding of how the concept of green management can be positioned as part of the human resource function. The motivation is to highlight the importance of building sustainable and eco-friendly business, and to gain knowledge of the outcomes after adopting Green human resource management in the organizations.
\end{abstract}

Keywords: Green human resource management, Environmental performance, Environmental practices

JEL classification: $015, Q 56$

\section{INTRODUCTION}

The thought of "green business" started to expand at the end of the XX century simultaneously with the continually growing concern about the sustainability of the economic development. While the starting points of the modern "green developments" are found in the middle of the 1960 s, it took nearly twenty years for businesses to align with the "greening" inclines and integrate them into its value systems and to put effort to beget the term green business.

There are numerous reasons behind this. One is related to the fact that the pursuit of green business is still mostly considered as an extra burden (as far as cost increment or profit loss). The other is related to the country's factors like the political, social, and monetary differences. Brown and Ratledge (2011, p. 2) define the green business as "an institution that produces green output". Makower and Pyke (2009), on the other hand, say that the green business demands a dedication towards financial gain, sustainability and humankind. The Business Dictionary states that the green business is "a business working in a way that has no harmful effects on the environment, the community, or the economy". 
These organizations integrate more sustainable business activities than the rivals, enhance the natural environment and improve the living conditions, while profiting and adding to the economy.

Slovik (2013) suggests a correlation between the sustainable practices and the social commitment: "a green business" is a business that utilizes renewable resources (environmentally responsible) and it is responsible for the HR part of their activities (socially responsible)".

In other words, these organizations except focusing only on the main goal, which is profit, they also focus on fields like conserving the environment, improving the community's life quality, usage of renewable resources, cost reduction, reducing the amount of waste.

According to Kassaye (2001), an ecologically mindful organization ought to take a commitment to one of "4Rs" - reduction, reuse, recycle and recovery.

Some organizations advice their workers to utilize public transport as opposed to private vehicles with a specific end goal to decrease air contamination or to refuel the car after six p.m. at the point when the gas exhausts are less destructive to the environment. We ourselves are witnesses of how much the air quality has improved during the pandemic.

\section{THEORETICAL FRAMEWORK}

\subsection{Defining the concept and the determination of methods of work}

To realize an ecological mindfulness into an association is different according to various kinds of changes, because it is a subsidiary's aim of the company. Eco-friendly companies are essential to customers, yet since this performance will never be the principle objective of an organization, it should be contended that they should put effort to achieve their primary objectives in an eco-friendly way. This demands a change in the organizations' attitude and culture (Borland, 2009).

If the organization wants to be capable of executing an ecological conduct, the organization's culture must be adapted and focused on the environment, and the management must show a dedication towards building an environmentally friendly organization. Organizational cultures have grasped the desired qualities needed for achieving competitive advantage, while at the same time promoting effective ecological execution. Some researches state that the representatives are the ones who through their everyday work can realize the environmental activities, which leads to the conclusion that the accomplishment of the ecological targets in evitable depends upon the willingness and commitment of the representatives to change their work practices.

When the management wants to bring and establish ecological values in the organization, the best approach is through changing of the organizational culture. The Motivation of the employees is essential in the change of the organizational culture. That what motivates representatives may be the money or different advantages, however in the case that the association is eco-friendly itself can act as an inspiring variable.

The significance of communication as a tool to include and engage workers during cultural and overall organizational developments is continuously highlighted by the researches (Andre, 2013). In case those representatives are not completely acquainted of the developments which are undertaken, it may convey misunderstanding and prompt resistance to change. For the change to be executed effectively, it should be founded on open interactions.

In the previous decade, the organizations started to focus their attention on the issue of environmental change and sustainability. Various opinions have emerged on the matter why associations should be more environmentally friendly; however, despite the general affirmation of this green necessity, progress stays moderate. Whilst extensive arguing continues over the relative effect of innovative green technology and the roles of governments, international bodies 
and private and public sector associations, the truth is that the pro- environmental conduct relies upon individual behavior. Everyone has a part to play and the part of the organizations will essentially be manifested through the people that work in and for them.

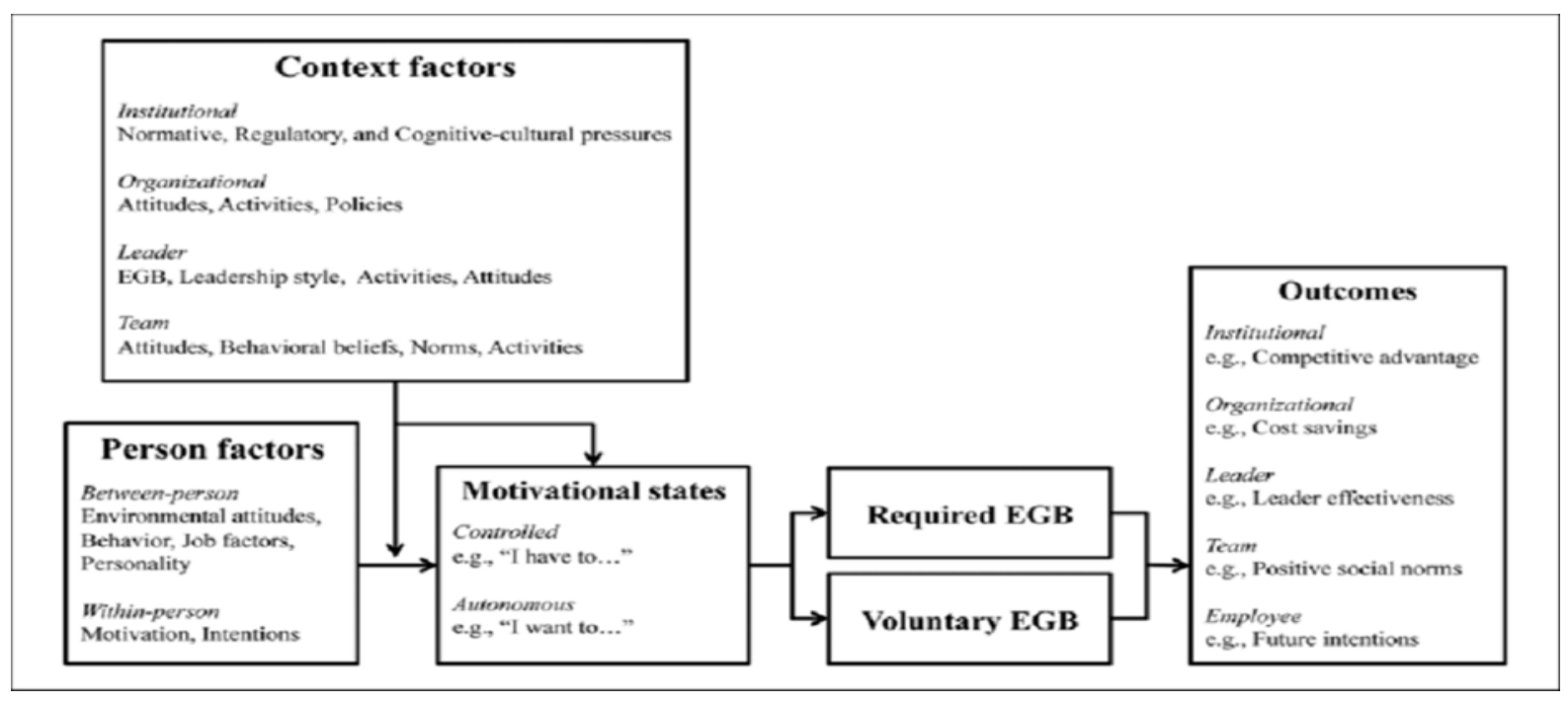

Source: Norton et al, Employee Green Behaviour: A theoretical framework, multilevel review, and future research agenda, 2015, pg. 104.

First, the model is founded on the viewpoint that performance is the function of a person and their environment. More particularly, inside this perspective, the conduct is a consequence of a person's ability and general eagerness to perform, along with other influences which are not controlled by a person.

Second, the job performance includes required and voluntary activities. By utilizing an approach based on job performance, Norton et al. conceptualizes worker's green behavior as a particular kind of work performance that corresponds with environmental sustainability, different from the environmental conduct which just happens to be implementedin the work surroundings. Basic to their methodology is evaluation for the significance of the factors which are not controlled by the individuals, but nevertheless influence the conduct, especially in connections where the person has decreased authority over its own activities, for example, in the working environment.

\section{Green Human Resources Management-Performance Management \& Appraisals}

Performance management (PM) is the process by which employees are prompted to enhance their professional skills that help to achieve the organizational goals and objectives in a better way. Therefore, in order to create a greener company, performance appraisal (PA) systems can include sustainability goals (that come from a sustainability strategy done previously) measured with specific metrics.

While this accountability may be easily done in some jobs, one of the biggest obstacles of green PA is the difficulty to measure and gain data on environmental performance standards across different organizational departments/units. To help overcome this, companies can start using global systems that help them to collect data and at the same time give them advice on how they can become more sustainable and gets them a certificate for that, such as ISO 14001 or the Global Reporting Initiative.

When it comes to the PA of managers, green targets, goals, and responsibilities such as creating green awareness in their teams and encouraging them to get involved in green activities of the company can also be considered. In the end, the ultimate goal of green PM is to have a 
measurable outcome of an organization's ability to meet its ecological objectives and targets set forth in the organization's environmental plans or policies.

\section{Green Human Resources Management - Employee Relations \& Ways of going green}

To help to build a sustainable company it is crucial to promote 'eco-intrapreneurs' that add value to the organization's products and/or services with efficient utilization of existing financial, human and natural resources. This often means encouraging employees to get involved and participate in the social and environmental initiatives organized by the company.

Some examples of practices that employees could get engaged with are:

To cut on carbon emissions: using car-sharing; taking advantage of the free or discounted transportation passes and hybrid/electric cars offered by the company; walking or cycling to work; working from home day once or twice a week;

To reduce waste: using porcelain mugs and glasses for tea and coffee; promoting the $3 \mathrm{R}$ 's reduce, reuse and recycle; using electronic archives and electronic signatures to avoid wasting paper.

\section{METHODOLOGICAL FRAMEWORK AND RESEARCH DISCUSSION}

\subsection{Methodology and description}

\section{An analysis of green human resource management in Gorenje}

The empirical part introduces the green HRM and the process of integrating the green in the strategy process of Gorenje Group, and examines the challenges the corporation has in implementing and communicating green practices to the employees. The research questions are:

1. Which Green human resource practices Gorenje implements?

2. How Green practices increase the success and brand recognition of Gorenje?

Lastly, an interview process with seven Gorenje's managers is presented, thus providing a better overview of the green practices and processes the company executes.

One of the essential Gorenje's considerations is the protection of the environment, which is highly seated in all of its strategies for development. The approaches for the preservation of the environment involve the complete duration of a product, from planning, production, and usage, to disposal.

By using cutting edge technology, processes, and materials, Gorenje consistently diminishes the amount of wastage created in the manufacturing process and the utilization of energy and natural resources. Gorenje is among the first in Europe to decrease and subsequently completely abandon the use of ecologically hazardous refrigerants and propellants.

As a socially mindful organization, Gorenje as well works towards educating and improving the awareness of representatives and people in general about the environmental behavior and its importance. In 2006, the international certificate ISO 14001 was awarded to Gorenje; in 2004, it also became the first Slovenian companies that become part of the EMAS register (Gorenje Group, 2013). The Gorenje management considers that a company which operates in an environmental way gets a crucial advantage over its rivals. The EMAS certification indicates that responsibility to everyday advancement is an essential element of Gorenje's vision. The company operates on the principle of the following orientations:

1. All workers are actively involved in the policy. The company policies are the premise for consistent improvement setting goals in all key areas, including quality and environment.

2. Satisfaction of investors, customers and other interested actors is Gorenje's primary consideration. With high-quality products and pro-environmental project execution Gorenje acquires customers' trust. 
3. Gorenje is focused on long-term success on the domestic and foreign markets, the reputation and brand recognition.

4. All workers continually improve their work-related and other knowledge and experience. In addition to improving their skills Gorenje provides social security to employees, hence improving their loyalty to the company.

5. Gorenje is always concerned with commercially interesting projects by determining the requirements of potential buyers and with helping them to adjust rapidly.

6. Gorenje's focus is on the continual diminishment of environmental contamination with accentuation on preventive activity. This implies finding quality, innovative, aesthetic and environmental and efficient arrangements from planning, designing and project execution.

7. Concern for the environment is conveyed also by the advancement of renewable energy assets. Gorenje has established plants for cogeneration of electricity and heat by combustion or gasification of various types of biomass.

8. Gorenje regularly observes and meet regulatory needs, technical standards and other potential requirements and best practices related to the work execution.

9. The project execution reflects important balance between quality, environment, cost and timelines of implementation.

10. Gorenje strives to establish correct, fair and environmentally responsible relations with subcontractors and suppliers.

In evaluating the environmental effects which incorporate all changes to the surroundings, favorable or not, resulting partly or completely from the practices, appliances, and services, Gorenje considers (Gorenje Group, 2015):

1. Direct effect, i.e. direct impact of the practices over which the company has immediate responsibility; and

2. Indirect effect, i.e. the impact from other actors, in which case Gorenje influence on the volume, type and occurrence of the contamination.

Internal correspondence that involves environmental protection is organized through Works Council, system for submitting and rewarding valuable and important proposals known as "Sparks" ("Iskrice"), the twenty key system, internal newspapers, and coordinators for environmental protection and occupational safety and health. Representatives are educated about the occasions, practices and approaches in environmental work and occupational health and safety in the newsletters that are published every week.

The Gorenje's vision includes improving of the wellbeing and mindfulness of the surroundings. The Group's strategy involves a strong stands a pro-environmental manufacturer which results in changes in the use of new substances and energy. With the incorporation of new materials, procedures and innovations that minimize the damaging effects, Gorenje fully consents with the latest environmental standards.

Ecological management influences the design and execution of appliance development and production procedures. In the process of developing the products, Gorenje strives to diminish the appliance's final effect on the environment.

\section{CONCLUSION}

The above analysis recognizes that the significance of green human resource management practices is crucial to increase the employees' motivation and this may be advantage for both the organization and the employee. Some of the advantages that an association can accomplish as an after effect of presenting green human resource management standards in its management include:

1. Increasing the ability to retain the employees

2. Increasing brand recognition and improving the status of the company 
3. Attraction of most suitable representatives

4. Increasing the efficiency and sustainability

5. Minimizing or reducing the negative impact of the organization

6. Improving the competitive position and leading 999to a superior performance

More associations now understand the significance that sustainability has on their competitive position, status, and capacity to draw in and hold talent. Aware of their financial, social, and environmental effects, reasonable associations now search input from a wide set of actors both internally and externally - in molding their business systems and procedures. The human resource management has a crucial part to play. Using the human resource abilities in organizational procedures, change management and culture shaping, human resource management can help make and actualize sustainable business methodology all through the company. Not only human resource must become capable at using human resource management tools to implement the sustainability strategy, but also the mission in the organization should additionally learn how to change itself, so that its effect on workers, teams and different partners align to the vision for sustainability of the organization.

The purpose of this thesis was to investigate how the concept of green management can be positioned as part of the human resource function. As an example of successfully incorporated GHRM practices and sustainability programs, the case of Gorenje was investigated. The Gorenje vision incorporates the advancement of the quality of life and the responsibility for the surroundings. Gorenje's strategic plans involve a solid stance as a pro-environmental manufacturer, which has brought developments and reduction of the resource and energy consumption. Through the integration of new materials, procedures and advancements that reduce destructive effects on the surroundings, Gorenje works according to the newest environmental regulations. Environmental management influences the designing and executing of the appliance development and the related production processes. The environmental friendly approach and its application in all human resource practices is that what makes Gorenje one of the leading companies in Europe.

For a better review of the green human resource practices of Gorenje's Group, a qualitative study was performed. Structured interviews with seven employees from different managerial positions were conducted. The interview participants confirmed the conclusions gained from the theoretical part. Managers have a determining role in implementing an environmental management system in an organization. Gorenje's human resource management develops strategies to foster proactive environmental management through strong and highly visible top management commitment, development of training programs, strong internal environmental communication, development of green production and products, creation of performance evaluation and reward systems, implementing green programs and continuously improves in the area of environmental management.

Indeed, there are many gaps to be filled in terms of green human resource management, and theoretical and empirical research is needed in order to extend the knowledge on green human resource management. Notwithstanding, the green concept is becoming more and more important in the business environment (during the pandemic we saw how polluted our living areas were), and human resource management will have a crucial part in translating green policies in practice.

\section{REFERENCES}

Andre, J. M. (2013), "Plan do stabilize repeat: How to lead change successfully", Management Services, No. 57, Issue 1, pp. 42-47. 
Appels, C., Van D., L., \& Hamann, R. (2006), "Institutionalizing corporate citizenship: The case of Barlworld and its 'employee value creation' process", Developement of Southern Africa, Vol. 23 No. 2, pp. 241-250.

Aragon-Correa, J., A., Hurtado-Torres, N., Sharma, S., \& Garcia-Morales, V., J. (2008), "Environmental strategy and performance in small firms: A resource-based perspective", Journal of Environmental Management, Vol. 86 No. 1, pp. 88-103.

Boiral, O. (2009), "Greening the corporation through organizational citizenship behaviors", Journal of Business Ethics, Vol. 87, pp. 221-236.

Borland, H. (2009), "Conceptualising global strategic sustainability and corporate transformational change", International Marketing Review, Vol. 26 No. 4/5, pp. 554-572.

Boyce, C., \& Neale, P. (2006), "Conducting in-depth interviews: A guide for designing and conducting in-depth interviews for evaluation input. Watertown, MA: Pathfinder International. Brio, J. A., Fernandez, E., \& Junquera, B. (2007), "Management and employee involvement in achieving an environmental action-based competitive advantage: An empirical study", The International Journal of Human Resource Management, Vol. 18, pp. 491-522.

Business Dictionary, http://www.businessdictionary.com/definition/green-business.html Callenbach, E. (1993), EcoManagement: The Elmwood guide to ecological auditing and sustainable business. Berret-Koehler Publishers.

Carroll, A., B., \& Shabana, K., M. (2010), "The business case for corporate social responsibility: A review of concepts, research and practice", International Journal of Management Reviews, Vol. 12 No. 1, pp. 85-105.

Clemens, B. (2006), "Economic incentives and small firms: Does it pay to be green?", Journal of Business Research, Vol. 59, pp. 429-500.

Cohen, E., Taylor, S., \& Muller-Camen, M. (2012), HRM's role in corporate social and environmental sustainability, SHRM Foundation's Effective Practice Guidelines Series.

Egri, C. P., \& Herman, S. (2000), "Leadership in the North American environmental sector: Values, leadership styles, and contexts of environmental leaders and their organizations", Academy of Management Journal, Vol. 43, pp. 571-604.

Daly, H. E. (1996), Beyond growth: The economics of sustainable development. Beacon Press. Durning, A. T. (1992). How much is enough? The consumer society and the future of the earth, WW Norton \& Company.

Gilbert, C. G. (2005), "Unbundling the structure of inertia: Resource versus routine rigidity", Academy of Management Journal, Vol. 48, pp. 741-763.

Govindarajulu, N., \& Daily, B. F. (2004), "Motivating employees for environmental improvement", Industrial Management and Data Systems, Vol. 104, pp. 364-372.

Hanna, M. D., Rocky Newman, W. R., \& Johnson, P. (2000), "Linking operational and environmental improvement through employee involvement", International Journal of Operations and Production Management, Vol. 20, pp. 148-165.

Hartman, C. L., \& Stafford, E. R. (1997), "Green alliances: Building new business with environmental groups", Long Range Planning, Vol. 30, pp. 184-149.

Harvey, G., Williams, K., \& Probert, J. (2013), "Greening the airline pilot: HRM and the green performance of airlines in the UK", The International Journal of Human Resource Management, Vol. 24, pp. 152-166.

Hofer, C., Cantor, D. E., \& Dai, J. (2012), "The competitive determinants of a firm's environmental management activities: Evidence from US manufacturing industries", Journal of Operational Management, Vol. 30, pp. 69-84.

Jabbour, C. J. C. (2013a), "Environmental training in organisations: From a literature review to a framework for future research", Resources, Conservation and Recycling, Vol. 74, pp. 144 155. 
Kotler, P., Wong, V., Sauders, J., \& Armstrong, G. (2005), Principles of Marketing (4th ed.). New Jersey: Pearson Education.

May, D., R., Flannery, B., L. (1995), "Cutting waste with employee involvement teams", Business Horizons, Vol. 38 No. 5, pp. 28-38.

Meyer, J., P., Becker, T., E., \& Vandenberghe, C. (2004), "Employee commitment and motivation: A conceptual analysis and integrative model", Journal of Applied Psychology, Vol. 89 No. 6, pp. 991.

Norton, T., A., Parker, S., L., Zacher, H., \& Ashkansy, N., M. (2015), "Employee green behaviour a theoretical framework, multilevel review, and future research agenda", Organization \& Environment, Vol. 28 No. 1, pp. 103-125.

Olson, E. G. (2008), "Creating an enterprise-level "green" strategy", Journal of Business Strategy, Vol. 29 No. 2, pp. 22-30.

Prasad, P., \& Elmes, M. (2005), "In the name of the practical: Unearthing the hegemony of pragmatics in the discourse of environmental management", Journal of Management Studies, Vol. 42, pp. 845-867.

Ramus, C. A. (2001), "Organizational support for employees: Encouraging creative ideas for environmental sustainability”, California Management Review, Vol. 43, pp. 85-105.

Ramus, C. A. (2002). Encouraging innovative environmental actions: What companies and managers must do. Journal of World Business, 37, 151-164.

Ramus, C. A., \& Steger, U. (2000), "The roles of supervisory support behaviors and environmental policy in employee 'ecoinitiatives' at leading-edge European companies", Academy of Management Journal, Vol. 43, pp. 605-626.

Renwick, D., Redman, T., \& Maguire, S. (2008), "Green human resource management: A review, process model and research agenda", Discussion Paper, No 2008.01.

Renwick, D., Redman, T., \& Maguire, S. (2013), "Green human resource management: A review and research agenda", International Journal of Management Review, Vol. 15 No. 1, pp. $1-14$.

Robertson, J. L., \& Barling, J. (2013), “Greening organizations through leaders' influence on employees' pro-environmental behaviors", Journal of Organizational Behavior, Vol. 34, pp. 176-194.

Sustainable Green Certified Business (2013). Retrieved Ferbruary 01.2016, from http://www.greenin7.com/glossary/index.asp\#G

United Nations General Assembly. (1987). Report of the world commission on environment and development: Our common future. Oslo, Norway: United Nations General Assembly, Development and International Co-operation: Environment.

Wagner, M. (2013), "Green human resource benefits: Do they matter as determinants of environmental management system implementation?", Journal of Business Ethics, Vol. 114 No. 3, pp. 443-456.

Wehrmeyer, W. (1996), Greening people, Sheffield, England: Greenleaf Publishing.

Wossen, K. W. (2001), “Green dilema”, Marketing Intelligence \& Planning, Vol. 19 No. 6, pp. 444-455. 